\title{
Electrochemical Stability of Quaternary Ammonium Cations: An Experimental and Computational Study
}

\author{
Maral P. S. Mousavi, ${ }^{a}$ Sadra Kashefolgheta, ${ }^{b, z}$ Andreas Stein, ${ }^{a}$ and Philippe Bühlmannn ${ }^{a, w, z}$ \\ ${ }^{a}$ Department of Chemistry, University of Minnesota, Minneapolis, Minnesota 55455, USA \\ ${ }^{b}$ Department of Theory and Bio-Systems, Max Planck Institute of Colloids and Interfaces, Potsdam 14476, Germany
}

\begin{abstract}
Quaternary ammonium ions, $\mathrm{NR}_{4}{ }^{+}$, are among the most electrochemically stable organic cations. Because of their wide electrochemical windows, they are frequently used in batteries and electrochemical capacitors. Improving the electrochemical stability and expanding the electrochemical windows of quaternary ammonium ion is highly desired. In this work, we investigated the electrochemical stability of quaternary ammonium ions and showed that the chain length, type (primary vs. secondary), size, and steric hindrance of the saturated alkyl substituents have only a very small effect (less than $150 \mathrm{mV}$ ) on their electrochemical stability toward reduction. To provide a molecular understanding of substituent effects on electrochemical stability, quantum calculations were performed employing density functional theory, and it was shown that the structure of saturated aliphatic alkyl substituents has only minimal effects on the electronic environment around the positive nitrogen center and the LUMO energy level of quaternary ammonium cations. Moreover, a linear correlation between the cathodic limit and the LUMO energy levels of the $\mathrm{NR}_{4}{ }^{+}$, $\mathrm{N}$-butylpyridinium, and 1-ethyl-3-methylimidazolium ions was found, suggesting that electrochemical stabilities of new cations may be computationally predicted on the basis of LUMO energies of these systems.

(C) The Author(s) 2015. Published by ECS. This is an open access article distributed under the terms of the Creative Commons Attribution Non-Commercial No Derivatives 4.0 License (CC BY-NC-ND, http://creativecommons.org/licenses/by-nc-nd/4.0/), which permits non-commercial reuse, distribution, and reproduction in any medium, provided the original work is not changed in any way and is properly cited. For permission for commercial reuse, please email: oa@electrochem.org. [DOI: 10.1149/2.0671602jes] All rights reserved.
\end{abstract}

Manuscript submitted July 27, 2015; revised manuscript received November 12, 2015. Published November 24, 2015.

With the increasing global demand for energy, improving existing energy storage technologies is as critical as developing more efficient methods for energy production. For one important class of energy storage technologies, namely electrical energy storage, the energy density of a device is usually limited by the voltage window in which the device can function. Therefore, expanding the working voltage range of such devices is highly desired. The electrochemical decomposition of electrolytes, which are commonly used in energy storage devices such as electrochemical capacitors, often limits the useful voltage window ${ }^{1}$ because these devices can function properly only within the electrochemical window of their electrolyte. Modifying the structure of electrolytes and improving their electrochemical stabilities has been the focus of numerous studies to date. ${ }^{2-15}$

The electrochemical window of an electrolyte is the voltage range in which the electrolyte is chemically stable and does not get reduced or oxidized as a result of the applied potential. ${ }^{16}$ The upper end of the electrochemical window is usually limited by the oxidation of the anion, and the lower end of the electrochemical window is determined by the reduction of the cation. ${ }^{1}$ One of the most electrochemically stable classes of organic cations comprises the quaternary ammonium ions, $\mathrm{NR}_{4}{ }^{+}$. These are highly inert toward reduction, offer wide electrochemical windows, and are, therefore, frequently used in batteries and capacitors. ${ }^{2,5,6,17}$ Much research has been devoted to improving the electrochemical stability of quaternary ammonium ions. ${ }^{4,9-15}$

Reduction of quaternary ammonium ions occurs via radical intermediates and involves the loss of an alkyl substituent., ${ }^{411,18-21}$ Therefore, the nature of the alkyl substituents strongly affects the electrochemical stability of these cations. ${ }^{9}$ Quaternary ammonium ions with aromatic substituents such as benzyl groups have lower electrochemical stabilities than saturated quaternary ammonium ions. ${ }^{11}$ This effect is likely due to the higher stability of benzyl radicals as compared to alkyl radicals, making the former a better leaving group, and thus making quaternary ammonium ions with benzyl substituents more sensitive to reduction. ${ }^{11}$ Incorporation of oxygen atoms in the alkyl substituents of quaternary ammonium ions also diminishes their electrochemical stability toward reduction, likely due to the electrostatic

*Electrochemical Society Active Member.

zE-mail: Sadra.kashef@mpikg.mpg.de; Buhlmann@umn.edu effects of the oxygen atoms. ${ }^{10,12-15}$ Changing the structure of the saturated alkyl substituent (increasing the alkyl chain length, size, etc.) can also affect the electrochemical stability of quaternary ammonium ions. Unfortunately, there are discrepancies in the literature on this topic.

Several reports have indicated that increasing the chain length or size of alkyl substituents in quaternary ammonium ions improves the electrochemical stability of these ions..$^{2,9-12,22,23}$ The increased stability was attributed to the higher blocking and shielding effect and increased electron donating characteristics of larger alkyl groups. ${ }^{9,11,22}$ In contrast, no substantial improvement in the cathodic stability of quaternary ammonium ions was observed in another study upon increasing the length of the alkyl substituent. ${ }^{3}$ Yet another study reported a decreased electrochemical stability of quaternary ammonium ions toward reduction with increasing chain length of the alkyl substituent. ${ }^{18}$ There are also discrepancies in what has been reported on the effect of ion size on the electrochemical properties of quaternary ammonium cations. Increasing the cation size was concluded in one study to increase electrochemical stability, ${ }^{10}$ whereas another one found no such result. ${ }^{3}$ The effect of the alkyl substituent is not only a function of size, but the nature of the alkyl group is also important, as structurally isomeric alkyl groups are expected to have different effects on the electrochemical stability of quaternary ammonium ions. For example, changing the quaternary ammonium substituent from butyl to iso-butyl was reported to improve electrochemical stability. ${ }^{2,9}$ However, changing from a primary to a secondary alkyl substituent was reported to drastically reduce electrochemical stability in one study $(n-\mathrm{Bu} \text { to } s-\mathrm{Bu})^{9}$ and to improve electrochemical stability in another ( $n$-Pr to $i$-Pr). ${ }^{2}$ Clearly, there is a need to clarify the aforementioned discrepancies.

In this work, we provide a comprehensive investigation of the effect of a series of alkyl substituents on the electrochemical stability of quaternary ammonium cations. The effect of alkyl chain length, size, and type (i.e., primary vs. secondary alkyl groups) is studied. Our findings are compared to published reports, and the discrepancies in the literature are discussed and explained. In addition to the experimental characterization of the electrochemical stabilities of quaternary ammonium cations, the lowest unoccupied molecular orbital (LUMO) energy levels of quaternary ammonium cations were calculated using the time-dependent density functional theory, ${ }^{24-26}$ TD-DFT, method, providing a molecular understanding of the electrochemical behavior of these cations. 


\section{Experimental}

Electrochemical measurements. - Linear sweep voltammetry experiments were carried out with a $\mathrm{CHI} 600 \mathrm{C}$ potentiostat $(\mathrm{CH}$ Instruments, Austin, TX). A three-electrode set up with a $3.0 \mathrm{~mm}$-diameter glassy carbon (GC) disk working electrode (BAS, West Lafayette, IN), a $0.25 \mathrm{~mm}$ Pt wire coil (99.998\%, Alfa Aesar, Ward Hill, MA) auxiliary electrode, and $\mathrm{a}^{+} / \mathrm{Ag}$ reference electrode (reference solution: $10 \mathrm{mM} \mathrm{AgNO}_{3}$ and $100 \mathrm{mM} \mathrm{NBu}_{4} \mathrm{ClO}_{4}$ in acetonitrile) was used for all measurements (scan rate: $100 \mathrm{mV} / \mathrm{s}$ ). The reference electrode was prepared in house according to a previously described procedure..$^{27,28}$ The distance between the working and reference electrode was kept small $(\approx 0.5 \mathrm{~cm})$ to minimize the $I R$ drop while not physically obstructing the working electrode. The working electrode was polished on Microcloth polishing pads using $5.0 \mu \mathrm{m}$ Micropolish II deagglomerated alumina, both from Buehler (Lake Bluff, IL). After polishing, the electrode was rinsed thoroughly with deionized water and then with ethanol, followed by drying under a stream of Ar. The anhydrous solvents used in this work were stored and transferred under argon. Prior to measurements, all solutions were purged with argon for $15 \mathrm{~min}$ while stirring vigorously to remove dissolved oxygen. The magnitude of the capacitive current was less than $0.02 \mathrm{~mA} / \mathrm{cm}^{2}$. All quaternary ammonium salt solutions were $300 \mathrm{mM}$ in concentration, except for the $\mathrm{NEt}_{4} \mathrm{I}$ solution, which was $100 \mathrm{mM}$ due to the limited solubility of this salt. The different concentration of $\mathrm{NEt}_{4} \mathrm{I}$ is not a concern because we are reporting cathodic stabilities measured by the linear fit method, which corrects for the effect of electrolyte concentration on the electrochemical stability limits. Information about the synthesis of quaternary ammonium species and material vendors is provided in the Supporting Information.

A 1255B frequency response analyzer and a SI 1287 electrochemical interface from Solartron (Farnborough, Hampshire, UK) with a conductivity cell from Cole-Parmer (Vernon Hills, IL, USA) were used to determine the specific resistivity of propylene carbonate solutions of the quaternary ammonium iodides. A $500 \mu \mathrm{S} / \mathrm{cm}$ conductivity standard solution was used to determine the cell constant. Resistances were obtained by fitting of impedance spectra with ZView2 software (Scribner Associates, Southern Pines, NC, USA) in the $10^{4}$ to $10^{5} \mathrm{~Hz}$ range. A specific resistivity of $7.1 \pm 0.4 \Omega \mathrm{m}$ was obtained for the propylene carbonate solution of $300 \mathrm{mM}$ tetrabutylammonium iodide. The specific resistivity of the remaining quaternary ammoniums used in this study is expected to be close to the specific resistivity of $\mathrm{NBu}_{4} \mathrm{I}$, as it was shown that the chain length of substituents (ethyl to hexyl) and the symmetry of quaternary ammonium salts changes the specific conductivity by less than $10 \% .^{29-31}$ The $I R$ drop across the working and reference electrodes at current densities of 1 to $5 \mathrm{~mA} / \mathrm{cm}^{2}$ is less than $1 \mathrm{mV}$ in this study. $\left(I R=J A(\rho L / A)=J \rho L=5 \mathrm{~mA} \mathrm{~cm}{ }^{-2}\right.$ $\times 0.071 \Omega \mathrm{cm} \times 0.5 \mathrm{~cm}<1 \mathrm{mV}$, where $A$ is the area of the working electrode, $L$ is the distance between the reference and working electrodes, $\rho$ is the specific resistivity of the solution, and $R$ is the solution resistance.)

Computational methods. - To calculate the LUMO and HOMO energies of the quaternary ammonium cations, density functional theory (DFT) was used as the quantum mechanical method. ${ }^{32}$ All structures were optimized to reach the lowest ground state energy. The structures of cations were optimized using the DFT method with the B3LYP density functional ${ }^{33-36}$ and the triple-zeta basis set 6$311++(\mathrm{d}, \mathrm{p})$. To take into account solvation effects, DFT was combined with the polarizable continuum model IEF-PCM ${ }^{37-41}$ for propylene carbonate (see Supporting Information for details). This is an implicit solvation model in which the solvent has no molecular structure, and solvent effects are approximated by creating a solvent cavity around the solute molecules using macroscopic parameters for, for e.g., the solvent dielectric constant and the solvent radius. As a part of the optimization process, the energies of all occupied and unoccupied molecular orbitals are calculated. DFT HOMO energies (Kohn-Sham HOMO eigenvalues) were reported to have a linear correlation with experimental ionization potentials. However, LUMO energies (KS
LUMO eigenvalues) from DFT show poor correlation with the experimental LUMO energies. ${ }^{32,42,43}$ (An experimental LUMO energy is defined as the difference between the experimental ionization potential and the experimental first excitation energy.) ${ }^{32}$

A better estimate of LUMO energies can be obtained by calculation of the first excitation energy using the time-dependent density functional theory (TD-DFT), followed by addition of the resulting value to the calculated energy for the HOMO (see Supporting Information for details). The TD-DFT is an extension of the DFT method for the treatment of time-dependent phenomena such as excitation energies, and assumes the electron density to be a function of time in addition to space. ${ }^{24}$ The excitation energies (HOMO-LUMO energy gaps) obtained with TD-DFT were reported to have a good linear correlation with respect to the experimental values, and, therefore, the LUMO energies that are obtained this way are expected to be more reliable than the directly calculated Kohn-Sham LUMO eigenvalues. ${ }^{32}$ All calculations were performed with the Gaussian03 package. ${ }^{44}$ Cartesian coordinates of cations are provided in the Supporting Information.

\section{Results and Discussion}

Reduction of quaternary ammonium cations occurs by quantum tunneling of an electron from an occupied state at the Fermi energy level of the electrode to the LUMO of the cation. ${ }^{23,45}$ The rate of electron transfer is maximized when the electrode Fermi level reaches the cation LUMO energy level. ${ }^{45}$ The structure of the alkyl groups can affect the LUMO energy level of the quaternary ammonium, consequently affecting its electrochemical stability. Electron donating alkyl groups can decrease the positive charge density of the nitrogen atom in the quaternary ammonium ion and improve its stability toward reduction. The rate of electron transfer is also affected by the donor-acceptor distance, decaying exponentially as the donoracceptor distance increases. ${ }^{23}$ As any cations, at negative potentials quaternary ammonium ions adsorb electrostatically onto the electrode surface, and the electron transfer occurs over a short-range distance. ${ }^{23}$ Bulkier or more sterically hindered alkyl groups may increase the tunneling distance, reduce the rate of electron tunneling to the LUMO, and consequently increase the stability of the quaternary ammonium toward reduction. ${ }^{23}$ To study such effects, we investigated the series of quaternary ammoniums displayed in Scheme 1. Parameters such as alkyl chain length $\left(\mathrm{RNR}_{3}{ }^{+}\right.$, where $\mathrm{R}$ is $\mathrm{Me}, \mathrm{Et}$, $\mathrm{Pr}$, or $\mathrm{Bu}$ and $\mathrm{R}^{\prime}$ is $\mathrm{Pr}$ or $\mathrm{Bu}$ ), the size of the quaternary ammonium cation $\left(\mathrm{NR}_{4}{ }^{+}\right.$, where $\mathrm{R}$ is $\mathrm{Me}, \mathrm{Et}, \mathrm{Pr}, \mathrm{Bu}$, Pent, or Hex) and the nature of the alkyl substituent (as in $\mathrm{MeN}(i-\mathrm{Bu})_{3}{ }^{+}, \mathrm{Et}_{2} \mathrm{~N}(i \text {-Pr })_{2}{ }^{+}$, or $\mathrm{MeEtN}(i-\mathrm{Pr})_{2}{ }^{+}$) were varied to understand the different structural effects on the electrochemical stability of these cations and address the discrepancies in the literature that were highlighted in the introduction.

Assessment of the electrochemical stability of electrolytes: origin of discrepancies. - Many of the discrepancies in the reported effects of substituents on the electrochemical stability of quaternary ammonium cations are likely caused by two reasons: lack of robustness in the method used for quantifying the electrolyte electrochemical stability, and lack of properly addressing the reproducibility of the results. In the past, the determination of the electrochemical stability limit of electrolytes has not been well defined. Usually, a currentvoltage polarization curve has been measured, and the voltage at which a specific current density, $J$, is reached, has been defined as the cathodic or anodic electrochemical limit of the electrolyte (see Figure 1A). ${ }^{16}$ The choice of the cutoff current density, $J_{\text {cut-off }}$, is quite arbitrary, and a number of $J_{\text {cut-off }}$ values $\left(0.01\right.$ to $\left.5.0 \mathrm{~mA} / \mathrm{cm}^{2}\right)$ have been used in the literature..$^{2-4,6,8-15,46-51}$ Unfortunately, the choice of $J_{\text {cut-off }}$ can influence the electrochemical limit of electrolytes by as much as $0.9 \mathrm{~V} \cdot{ }^{4,51}$ Figure 1 shows the linear sweep voltammogram of $\mathrm{NEt}_{4} \mathrm{I}$; the voltages at which $J_{\text {cut-off }}$ values of 0.5 and $1.0 \mathrm{~mA} / \mathrm{cm}^{2}$ are reached are shown in Panel A. Clearly, the choice of the $J_{\text {cut-off }}$ value affects the electrochemical limit determined for $\mathrm{NEt}_{4} \mathrm{I}$. In addition to the value of $J_{\text {cut-off }}$, parameters such as electrolyte concentration and conductivity can bias the determined electrochemical limit by as 
<smiles>CCCC[n+]1ccccc1</smiles>
$\mathrm{NPyBu}^{+}$<smiles>CCC[N+](C)(CCC)CCC</smiles><smiles>[14CH3][18F]</smiles><smiles>CC(C)C[N+](C)(CC(C)C)CC(C)C</smiles>

$\operatorname{MeN}(i-B u)_{3}^{+}$<smiles>CC[n+]1cn(C)c[15n]1</smiles><smiles>[Z17][NH2+]CC</smiles><smiles>CCCC[N+](CC)(CCCC)CCCC</smiles><smiles>CCN(CC)CC</smiles><smiles>CCC[N+](CCC)(CCC)CCC</smiles><smiles>CCCC[Nb](CCCC)(CCCC)CCCC</smiles><smiles>CCCC[N+](CCCC)(CCCC)CCCC</smiles>
$\mathrm{PrNBu}_{3}^{+}$<smiles>CCC[N+](CC)(CCC)CCC</smiles>

$\operatorname{EtNPr}_{3}^{+}$

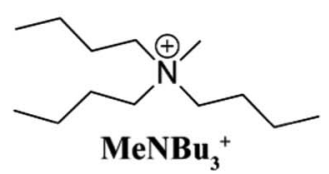<smiles>CC[N+](C)(C(C)C)C(C)C</smiles>

$\operatorname{EtNMe}(i \text {-Pr })_{2}^{+}$

Scheme 1. Structures and abbreviations of organic cations investigated in this study.

much as $500 \mathrm{mV} .^{1,51}$ Other experimental parameters, such as the type of the working electrode and the scan rate, have been found to affect the determined electrochemical limits to a lesser extent. ${ }^{1,4,51}$ In case of measurements performed with working electrodes with very high surface areas, such as porous carbon electrodes, the capacitive current may bias the determination of electrochemical limits by the cutoff current density method by as much as $2.0 \mathrm{~V} .{ }^{51}$ Therefore, electrolyte stability limits as reported by different authors do not solely represent
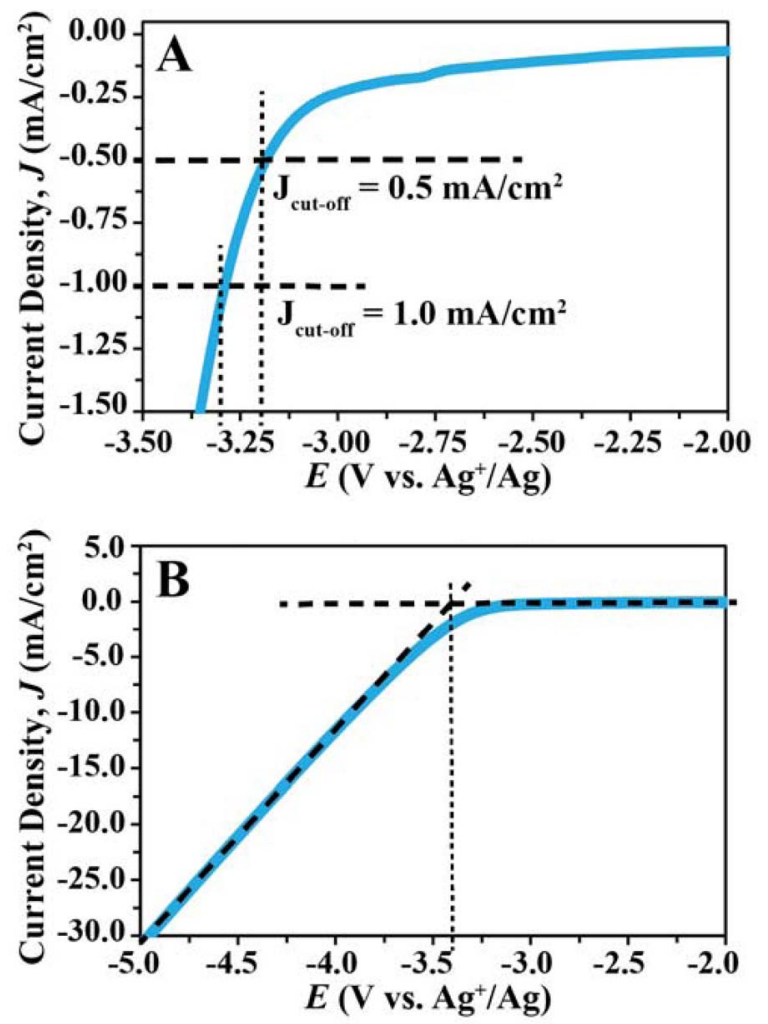

Figure 1. Determination of the electrochemical stability limit of electrolytes. (A) and (B) show the linear sweep voltammograms of $\mathrm{NEt}_{4} \mathrm{I}(100 \mathrm{mM})$ in propylene carbonate. Panel (A) illustrates the use of $J_{\text {cut-off }}$ values of 0.5 and $1.0 \mathrm{~mA} / \mathrm{cm}^{2}$. The dashed lines in panel (B) are linear fits before and after the onset of $\mathrm{NBu}_{4} \mathrm{I}$ reduction; the vertical dotted line highlights the potential at which the two fits intersect. Scan rate, $100 \mathrm{mV} / \mathrm{s}$; Pt coil auxiliary electrode, $\mathrm{GC}$ working electrode, and $\mathrm{Ag}^{+} / \mathrm{Ag}$ reference electrode. the thermodynamic properties of the electrolyte but are affected by different experimental procedures and assessment criteria.

In our work, to assess the electrochemical stability of quaternary ammonium ions more comprehensively, we determined the electrochemical limit of these cations at $J_{\text {cut-off }}$ of $0.1,0.5,1.0$, and $5.0 \mathrm{~mA} / \mathrm{cm}^{2}$. The resulting values are presented in Table I, which shows that changes in $J_{\text {cut-off }}$ can shift electrochemical stability limits by as much as $1.8 \mathrm{~V}$. Moreover, the order of the electrochemical stability of the quaternary ammoniums changes when altering the $J_{\text {cut-off }}$ criterion. For instance, at $J_{\text {cut-off }}$ of 0.1 and $5.0 \mathrm{~mA} / \mathrm{cm}^{2}, \mathrm{NEt}_{4}{ }^{+}$is predicted to have a higher stability toward reduction than $\mathrm{NHex}_{4}{ }^{+}$; however, at 0.5 and $1.0 \mathrm{~mA} / \mathrm{cm}^{2}$ the order is reversed, and $\mathrm{NHex}_{4}{ }^{+}$has a higher electrochemical limit (see entries 3 and 7 in Table I). Similarly, changing the $J_{\text {cut-off }}$ criterion influences the order of the electrochemical stabilities of $\mathrm{MeNPr}_{3}{ }^{+}$and $\mathrm{BuNPr}_{3}{ }^{+}$as well as $\mathrm{MeN}(i-\mathrm{Bu})_{3}{ }^{+}$and $\operatorname{EtNMe}(i-P r){ }_{2}{ }^{+}$(see entries 11, 13, 14, and 15 in Table I). Even though not discussed by the authors of the original literature, this phenomenon can also be observed in the electrochemical stability limits of room temperature ionic liquids, where a different order of electrochemical stabilities for imidazolium-based ionic liquids is obtained at $J_{\text {cut-off }}$ of 1.0 and $5.0 \mathrm{~mA} / \mathrm{cm}^{2}{ }^{50}$ This confirms that small differences in the observed electrochemical stability limits should not be attributed hastily to the molecular properties such as electron donating or shielding effect of the alkyl groups, and the effect of experimental conditions and the $J_{\text {cut-off }}$ choice must be considered carefully.

Surprisingly, all the conclusions drawn in the literature regarding the electrochemical stability of quaternary ammoniums were based on single measurements, and data reproducibility was not investigated. The latter explains some of the contradictory reports on the electrochemical stability of quaternary ammoniums. In several cases, small differences in electrochemical stability limits were attributed to intrinsic properties of the electrolyte, and often it is not clear whether the observed differences are statistically significant or not. For instance, stability limits of -1.89 and $-1.95 \mathrm{~V}$ vs. $\mathrm{Ag} / \mathrm{AgCl}$ for $\mathrm{Et}_{3} \mathrm{NMeCl}$ and $\mathrm{Bu}_{3} \mathrm{NMeCl}$ were reported, respectively, and it was concluded that increasing the alkyl substituent chain length improves the electrochemical stability of quaternary ammoniums. ${ }^{11}$ Other examples include interpreting $50 \mathrm{mV},{ }^{9} 90 \mathrm{mV},{ }^{12} 140 \mathrm{mV},{ }^{11}$ and $160 \mathrm{mV}^{9}$ differences in the electrochemical limit of quaternary ammonium ions, without assuring statistical significance. In our analysis, we performed five replicates of the current-voltage polarization curves for each quaternary ammonium. As shown in Table I, standard deviations as high 80 $\mathrm{mV}$ at $J_{\text {cut-off }}$ of 0.5 to $5.0 \mathrm{~mA} / \mathrm{cm}^{2}$, and as high as $500 \mathrm{mV}$ at $J_{\text {cut-off }}$ of $0.1 \mathrm{~mA} / \mathrm{cm}^{2}$ were observed. Of course, the standard deviations reported here are specific to our measurements, and the data reproducibility is affected by many parameters that are not easy to control. In this study, we attempted to minimize the effect of these parameters 
Table I. Cathodic limits (V vs. $\mathrm{Ag}^{+} / \mathrm{Ag}$ ) from the cutoff current density and linear fit methods.

The cutoff current density method

\begin{tabular}{|c|c|c|c|c|c|c|}
\hline & & & & & & \multirow[b]{2}{*}{ Linear fit method } \\
\hline & & $J_{\text {cut-off }}=0.1 \mathrm{~mA} / \mathrm{cm}^{2}$ & $J_{\text {cut-off }}=0.5 \mathrm{~mA} / \mathrm{cm}^{2}$ & $J_{\text {cut-off }}=1.0 \mathrm{~mA} / \mathrm{cm}^{2}$ & $J_{\text {cut-off }}=5.0 \mathrm{~mA} / \mathrm{cm}^{2}$ & \\
\hline 1 & NPyBu TFSI & $-1.523 \pm 0.004$ & $-1.571 \pm 0.005$ & $-1.603 \pm 0.004$ & $-1.735 \pm 0.009$ & $-1.584 \pm 0.004$ \\
\hline 2 & EMI TFSI & $-1.905 \pm 0.423$ & $-2.513 \pm 0.008$ & $-2.559 \pm 0.005$ & $-2.725 \pm 0.046$ & $-2.550 \pm 0.019$ \\
\hline 3 & $\mathbf{N E t}_{4} \mathbf{I}^{*}$ & $-2.447 \pm 0.067$ & $-3.183 \pm 0.012$ & $-3.293 \pm 0.012$ & $-3.619 \pm 0.008$ & $-3.403 \pm 0.005$ \\
\hline 4 & $\mathrm{NPr}_{4} \mathrm{I}$ & $-2.507 \pm 0.594$ & $-3.261 \pm 0.005$ & $-3.341 \pm 0.005$ & $-3.623 \pm 0.008$ & $-3.396 \pm 0.004$ \\
\hline 5 & $\mathrm{NBu}_{4} \mathrm{I}$ & $-2.463 \pm 0.076$ & $-3.297 \pm 0.032$ & $-3.359 \pm 0.028$ & $-3.541 \pm 0.017$ & $-3.423 \pm 0.010$ \\
\hline 6 & NPent $_{4}$ I & $-1.995 \pm 0.126$ & $-3.201 \pm 0.005$ & $-3.287 \pm 0.004$ & $-3.501 \pm 0.008$ & $-3.394 \pm 0.007$ \\
\hline 7 & $\mathrm{NHex}_{4} \mathrm{I}$ & $-1.741 \pm 0.342$ & $-3.257 \pm 0.007$ & $-3.337 \pm 0.008$ & $-3.603 \pm 0.012$ & $-3.449 \pm 0.008$ \\
\hline 8 & $\mathrm{MeNBu}_{3} \mathrm{I}$ & $-1.371 \pm 0.268$ & $-3.123 \pm 0.046$ & $-3.275 \pm 0.041$ & $-3.509 \pm 0.038$ & $-3.390 \pm 0.040$ \\
\hline 9 & $\mathrm{EtNBu}_{3} \mathrm{I}$ & $-1.548 \pm 0.302$ & $-3.208 \pm 0.011$ & $-3.303 \pm 0.019$ & $-3.558 \pm 0.080$ & $-3.384 \pm 0.009$ \\
\hline 10 & $\mathrm{PrNBu}_{3} \mathrm{I}$ & $-1.929 \pm 0.049$ & $-3.061 \pm 0.038$ & $-3.377 \pm 0.039$ & $-3.671 \pm 0.172$ & $-3.453 \pm 0.018$ \\
\hline 11 & $\mathrm{MeNPr}_{3} \mathrm{I}$ & $-2.329 \pm 0.083$ & $-3.121 \pm 0.083$ & $-3.259 \pm 0.005$ & $-3.491 \pm 0.012$ & $-3.361 \pm 0.016$ \\
\hline 12 & EtNPr $_{3} \mathbf{I}$ & $-2.387 \pm 0.033$ & $-3.187 \pm 0.004$ & $-3.273 \pm 0.004$ & $-3.487 \pm 0.005$ & $-3.386 \pm 0.006$ \\
\hline 13 & $\mathrm{BuNPr}_{3} \mathrm{I}$ & $-1.917 \pm 0.019$ & $-3.241 \pm 0.005$ & $-3.315 \pm 0.003$ & $-3.541 \pm 0.005$ & $-3.464 \pm 0.002$ \\
\hline 14 & $\operatorname{MeN}(i-B u)_{3} \mathbf{I}$ & $-2.417 \pm 0.099$ & $-3.169 \pm 0.016$ & $-3.265 \pm 0.014$ & $-3.523 \pm 0.035$ & $-3.383 \pm 0.008$ \\
\hline 15 & $\operatorname{EtNMe}(i-\operatorname{Pr})_{2} I^{*}$ & $-2.631 \pm 0.018$ & $-3.133 \pm 0.004$ & $-3.251 \pm 0.005$ & $-3.623 \pm 0.004$ & $-3.400 \pm 0.002$ \\
\hline 16 & $\mathbf{E t}_{2} \mathbf{N}(i-\mathbf{P r})_{2} \mathbf{I}^{*}$ & $-2.647 \pm 0.019$ & $-3.051 \pm 0.004$ & $-3.163 \pm 0.004$ & $-3.605 \pm 0.006$ & $-3.400 \pm 0.001$ \\
\hline
\end{tabular}

*100 mM in propylene carbonate.

Scan rate, $100 \mathrm{mV} / \mathrm{s}$; auxiliary electrode, $\mathrm{Pt}$ coil; working electrode, $\mathrm{GC}$; reference electrode, $\mathrm{Ag}^{+} / \mathrm{Ag}$.

by using high purity quaternary ammonium salts, carefully polishing and cleaning the working electrode, and by decreasing the $I R$ drop between the working and reference electrodes to less than $1.0 \mathrm{mV}$. The latter was achieved by using high concentrations of quaternary ammonium salts to obtain low solution resistivity, and by minimizing the distance between the working and reference electrodes (see the Experimental section for details).

Linear fit method.- To improve the ability to compare different electrochemical limits, we recently developed a new method (referred to as the linear fit method) for assessing the electrochemical stability of electrolytes. ${ }^{1,51}$ Using this method, two linear fits are applied to the current-voltage polarization curve of the electrolyte at potentials below and above the onset of cathodic or anodic decomposition (see Figure 1B). The intercept of the two approximately linear portions of the current-voltage relationship below and above the electrochemical limit is defined as the cathodic or anodic limit of the electrolyte..$^{1,51}$ We recently showed that the linear fit method does not rely on any $J_{\text {cut-off }}$ value and minimizes effects of the scan rate, electrolyte concentration, diffusion coefficients, capacitive current, and $I R$ drop between the working and reference electrodes. ${ }^{51}$ Thereby, it provides electrochemical limits that are more representative of the inherent properties of the electrolyte and are less affected by experimental parameters. ${ }^{51}$ Electrochemical stability limits obtained from the linear fit method are also presented in Table I.

Effect of alkyl substituents on the electrochemical stability of quaternary ammonium ions. - Electrochemical stability measurements were carried out using propylene carbonate solutions of quaternary ammonium electrolytes because propylene carbonate has an electrochemical window wider than quaternary ammonium ions. ${ }^{1,2,5}$ The $J_{\text {cut-off }}$ of $0.1 \mathrm{~mA} / \mathrm{cm}^{2}$ did not provide a realistic assessment of electrochemical stabilities. A stability limit of $-2.507 \pm 0.594 \mathrm{~V}$ vs. $\mathrm{Ag}^{+} / \mathrm{Ag}$ was determined for $\mathrm{NPr}_{4} \mathrm{I}$ when using this $J_{\text {cut-off }}$ value, while clearly the onset of electrochemical reduction is not reached at this potential (see Figure 2). On the other hand, the $J_{\text {cut-off }}$ of $5.0 \mathrm{~mA} / \mathrm{cm}^{2}$ overestimates electrochemical stability $\left(-3.623 \pm 0.008 \mathrm{~V}\right.$ vs. $\left.\mathrm{Ag}^{+} / \mathrm{Ag}\right)$ and predicts stability limits that are well past the onset of reduction. Therefore, we consider hereon stability limits obtained from $J_{\text {cut-off }}$ values of 0.5 and $1.0 \mathrm{~mA} / \mathrm{cm}^{2}$ and also the linear fit method.

Effect of alkyl chain length/quaternary ammonium size.- In this work, we do not distinguish between the effects of the length of straight alkyl chains and the size of the corresponding quaternary ammonium ions because the two effects are clearly directly related to one another. Overall, we found no correlation between the alkyl chain length and the electrochemical stability of the quaternary ammonium ions. The linear sweep voltammograms of $\mathrm{NEt}_{4}{ }^{+}, \mathrm{NPr}_{4}{ }^{+}, \mathrm{NBu}_{4}{ }^{+}, \mathrm{NPent}_{4}{ }^{+}$, and $\mathrm{NHex}_{4}{ }^{+}$are shown in Figure 2. Visually, there seems to be no difference in the onset of reduction of the aforementioned cations. At $J_{\text {cut-off }}$ of 0.5 and $1.0 \mathrm{~mA} / \mathrm{cm}^{2}$, there is no significant difference in the cathodic stability of $\mathrm{NEt}_{4}{ }^{+}$and $\mathrm{NPent}_{4}{ }^{+}$. Similarly, the cathodic limits of $\mathrm{NPr}_{4}{ }^{+}, \mathrm{NBu}_{4}{ }^{+}$, and $\mathrm{NHex}_{4}{ }^{+}$are not significantly different, yet these ions are significantly more stable than $\mathrm{NEt}_{4}{ }^{+}$and $\mathrm{NPent}_{4}{ }^{+}$ by approximately $60 \mathrm{mV}$ (see entries 3 to 7 in Table I). The linear fit method shows that there is no significant change in the cathodic stability of $\mathrm{NR}_{4}{ }^{+}$by increasing the alkyl chain length from ethyl to propyl, butyl, and pentyl. However, going from $\mathrm{NEt}_{4}{ }^{+}$to $\mathrm{NHex}_{4}{ }^{+}$ results in a statistically significant improvement in the cathodic limit by $40 \mathrm{mV}$.

In the $\mathrm{RNPr}_{3}{ }^{+}$series (entries 4, and 11 to 13 in Table I), increasing the length of R from methyl to ethyl did not affect the electrochemical stability significantly. Further increasing the R to propyl and butyl did cause a statistically significant improvement in the cathodic stability at all three assessment criteria of $J_{\text {cut-off }}$ of 0.5 and $1.0 \mathrm{~mA} / \mathrm{cm}^{2}$, and

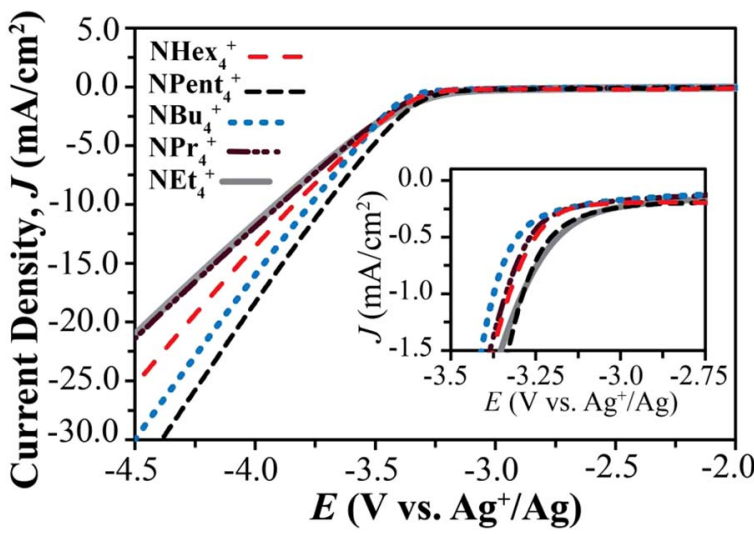

Figure 2. Linear sweep voltammograms of $100 \mathrm{mM} \mathrm{NEt}_{4} \mathrm{I}$, and $300 \mathrm{mM}$ $\mathrm{NPr}_{4} \mathrm{I}, \mathrm{NBu}_{4} \mathrm{I}, \mathrm{NPent}_{4} \mathrm{I}$, and $\mathrm{NHex}_{4} \mathrm{I}$ in propylene carbonate. Scan rate, 100 $\mathrm{mV} / \mathrm{s} ; \mathrm{Pt}$ coil auxiliary electrode, $\mathrm{GC}$ working electrode, and $\mathrm{Ag}^{+} / \mathrm{Ag}$ reference electrode. The inset zooms into the region where the onset of reduction occurs. 

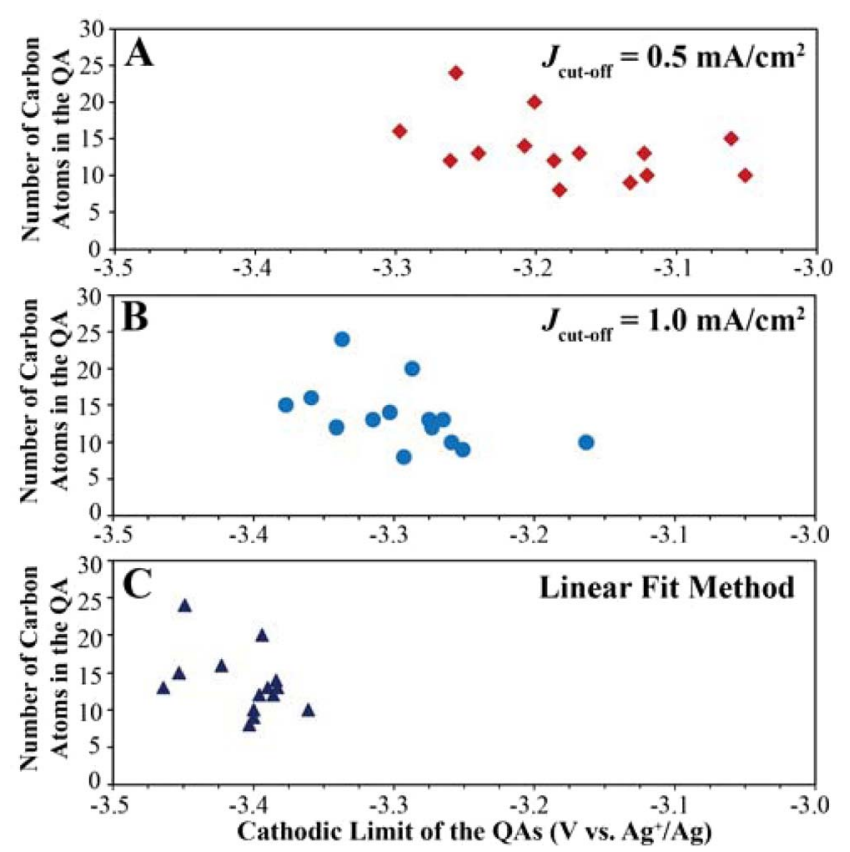

Figure 3. Dependence of cathodic limit of quaternary ammonium ions (QA) on the number of carbon atoms in their substituents. No correlation between the electrochemical stability (obtained by the $J_{\text {cut-off }}$ of 0.5 , and $1.0 \mathrm{~mA} / \mathrm{cm}^{2}$, and the linear fit method) and number of carbon atoms was observed.

the linear fit method. However, the magnitudes of the changes in the stability limit were small and less than $120 \mathrm{mV}$. Also, the electrochemical stabilities of $\mathrm{PrNPr}_{3}{ }^{+}$and $\mathrm{BuNPr}_{3}{ }^{+}$were not significantly different from one another.

For $\mathrm{RNBu}_{3}{ }^{+}$(entries 5, and 8 to 10 in Table I), increasing $\mathrm{R}$ from methyl to ethyl caused a significant improvement $(80 \mathrm{mV})$ in the stability limit at the assessment criterion of $J_{\text {cut-off }}$ of $0.5 \mathrm{~mA} / \mathrm{cm}^{2}$; however, $J_{\text {cut-off }}$ of $1.0 \mathrm{~mA} / \mathrm{cm}^{2}$ and the linear fit method did not predict a significant change in the cathodic stability. Changing $\mathrm{R}$ from methyl to propyl or butyl has no significant effect on the stability limit determined with the linear fit method and with the $J_{\text {cut-off }}$ of $0.5 \mathrm{~mA} / \mathrm{cm}^{2}$, but at $J_{\text {cut-off }}$ of $1.0 \mathrm{~mA} / \mathrm{cm}^{2}$ it results in a statistically significant improvement of $100 \mathrm{mV}$ in the stability limit. Finally, replacing methyl with butyl results in no significant effect on the stability limit determined with the linear fit method, and 174 and $90 \mathrm{mV}$ improvements in the cathodic stability at $J_{\text {cut-off }}$ of 0.5 and $1.0 \mathrm{~mA} / \mathrm{cm}^{2}$, respectively.

Clearly, increasing the alkyl chain length does not improve the cathodic limit consistently, the effects are relatively small (less than $150 \mathrm{mV}$ ), and different effects were observed for the different criteria of $J_{\text {cut-off }}$ of 0.5 and $1.0 \mathrm{~mA} / \mathrm{cm}^{2}$ and when using the linear fit method. This suggests that many of the observed changes in the cathodic stability are more an artifact of the cathodic limit quantification rather than an increased electrochemical stability in the molecular level. Figure 3 shows the relationship between the cathodic stability and the number of carbon atoms (representative of size) in the quaternary ammonium ions both for the linear fit and the $J_{\text {cut-off }}$ assessment methods. The overall range of observed cathodic limits was less than $150 \mathrm{mV}$. It is noticeable that the range of cathodic stabilities is narrower when these limits are determined with the linear fit method (Figure 3C), which is consistent with a lesser effect of electrolyte mass transport on this method. Using the linear fit method and the $0.5 \mathrm{~mA} / \mathrm{cm}^{2}$ data, no significant correlation between cathodic stabilities and the number of carbon atoms could be confirmed, even at the relaxed $\alpha$ of 0.1 (see the Supporting Information for results of the ANOVA test). A correlation between the cathodic stabilities measured as determined for a $J_{\text {cut-off }}$ value of $1.0 \mathrm{~mA} / \mathrm{cm}^{2}$ and the number of carbon atoms can be confirmed at the significance level of $90 \%$, but not at the sig-

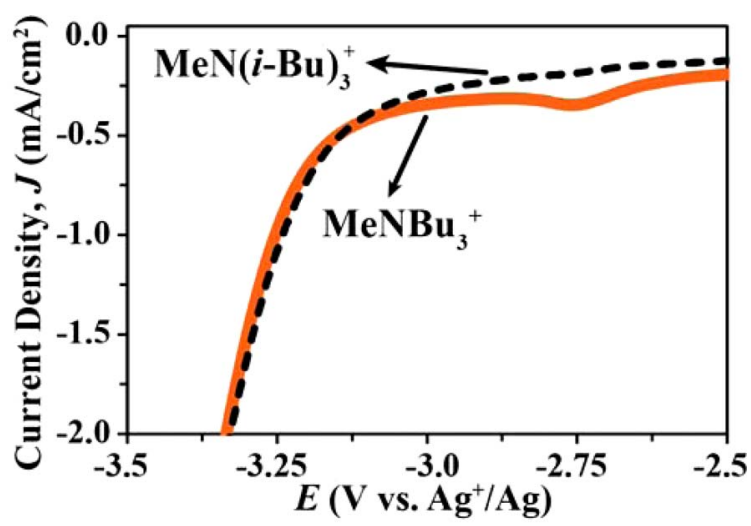

Figure 4. Effect of alkyl type. Linear sweep voltammograms of $300 \mathrm{mM}$ $\mathrm{MeNBu}_{3} \mathrm{I}$ and $\mathrm{MeN}(i-\mathrm{Bu})_{3} \mathrm{I}$. Solvent, propylene carbonate; scan rate, 100 $\mathrm{mV} / \mathrm{s}$; Pt coil auxiliary electrode, $\mathrm{GC}$ working electrode, and $\mathrm{Ag}^{+} / \mathrm{Ag}$ reference electrode.

nificance level of $95 \%$. This can be explained easily as an artifact of the $J_{\text {cut-off }}$ method since the cathodic limits measured with the $J_{\text {cut-off }}$ method are biased by the rate of cation transport to the electrode, which is affected by the cation's size and mass. A smaller diffusion coefficient along with an unchanged electrochemical stability results in no change in the onset of reduction, but a decrease in the slope of the current density vs. voltage relationship after the onset of reduction of the cation. ${ }^{51}$ Because larger cations diffuse more slowly, the slopes of their current density vs. voltage relationships after their onsets of reduction are smaller. Consequently cathodic stabilities as assessed by the $J_{\text {cut-off }}$ method are misjudged to be larger. This bias becomes larger the higher the $J_{\text {cut-off }}$ value is chosen.

Effect of alkyl type.- Similar linear sweep voltammograms were observed for $\mathrm{MeNBu}_{3}{ }^{+} \mathrm{I}^{-}$and $\mathrm{MeN}(i-\mathrm{Bu})_{3}{ }^{+} \mathrm{I}^{-}$(see Figure 4). No significant difference was noticed in the cathodic limits of the two cations at $J_{\text {cut-off }}$ of 0.5 and $1.0 \mathrm{~mA} / \mathrm{cm}^{2}$ and also the linear fit method (see Table I, which includes standard deviations). Our findings contradict those of $\mathrm{Xu}$ et al. who reported -0.11 and $-0.50 \mathrm{~V} \mathrm{vs.} \mathrm{Li}^{+} / \mathrm{Li}$ (which corresponds to -3.64 and $-4.03 \mathrm{~V}$ vs. $\left.\mathrm{Ag}^{+} / \mathrm{Ag}\right)^{52}$ for the cathodic limits of $\mathrm{MeNBu}_{3}{ }^{+} \mathrm{PF}_{6}{ }^{-}$and $\mathrm{MeN}(i-\mathrm{Bu})_{3}{ }^{+} \mathrm{PF}_{6}{ }^{-}$, respectively $\left(0.05 \mathrm{~mA} / \mathrm{cm}^{2}\right.$ as $J_{\text {cut-off }}$, working electrode: GC), and concluded that iso-butyl increases the cathodic stability. ${ }^{2}$ A similar conclusion was drawn elsewhere upon observing a $50 \mathrm{mV}$ improvement in the cathodic limit of $N$-alkyl- $N$-methyl-pyrrolidinium by changing the alkyl group from butyl to isobutyl. ${ }^{9}$ Both reports did not provide evidence that the observed differences in the cathodic limits were statistically significant.

Changing the alkyl group from $n$-Bu to $s$-Bu was previously reported to result in a more than $2.0 \mathrm{~V}$ decrease (no error range reported) in the cathodic limit $\left(0.1 \mathrm{~mA} / \mathrm{cm}^{2}\right.$ as $\left.J_{\text {cut-off }}\right)$ of $N$-alkyl- $N$ methyl-pyrrolidinium. ${ }^{9}$ Also, substituting the primary propyl groups in $\mathrm{Pr}_{3} \mathrm{NMe}^{+} \mathrm{PF}^{-}$by secondary isopropyl groups was reported to improve the cathodic limit $\left(0.05 \mathrm{~mA} / \mathrm{cm}^{2}\right.$ as $\left.J_{\text {cut-off }}\right)$ by $200 \mathrm{mV}$ (no error range reported). ${ }^{2}$ In contrast, we found that changing from primary to secondary alkyl groups has minimal effects on the cathodic stability of quaternary ammonium ions, as shown for $\mathrm{EtNPr}_{3} \mathrm{I}, \mathrm{Et}_{2} \mathrm{~N}(i-$ $\operatorname{Pr})_{2} \mathrm{I}$, and EtNMe $(i-\operatorname{Pr})_{2} \mathrm{I}$ in Table I (entries 12,15 , and 16). Replacing Pr with $i$-Pr resulted in a statistically significant decrease (less than $100 \mathrm{mV}$ ) in the magnitude of the cathodic limits at $J_{\text {cut-off }}$ of 0.5 and $1.0 \mathrm{~mA} / \mathrm{cm}^{2}$; however, it significantly improved the cathodic limits as determined with the linear fit method by $25 \mathrm{mV}$. This confirms that the small differences in the cathodic limits are most likely an artifact of experimental parameters rather than an intrinsic property of the cations with primary or secondary alkyl substituents.

Computational studies on the electrochemical stability of quaternary ammoniums. - Computational calculations can help to provide 


\begin{tabular}{|c|c|c|}
\hline Entry Number & Cation Structure & LUMO Energy \\
\hline 1 & $\mathrm{NPyBu}^{+}$ & -3.794 \\
\hline 2 & $\mathrm{EMI}^{+}$ & -2.096 \\
\hline 3 & $\mathrm{NEt}_{4}{ }^{+}$ & -1.287 \\
\hline 4 & $\mathrm{NPr}_{4}^{+}$ & -1.412 \\
\hline 5 & $\mathrm{NBu}_{4}^{+}$ & -1.363 \\
\hline 6 & $\mathrm{NPent}_{4}+$ & -1.274 \\
\hline 7 & $\mathrm{NHex}_{4}^{+}$ & -1.189 \\
\hline 8 & $\mathrm{MeNBu}_{3}{ }^{+}$ & -1.246 \\
\hline 9 & $\mathrm{EtNBu}_{3}{ }^{+}$ & -1.351 \\
\hline 10 & $\mathrm{PrNBu}_{3}{ }^{+}$ & -1.366 \\
\hline 11 & $\mathrm{MeNPr}_{3}{ }^{+}$ & -1.338 \\
\hline 12 & $\mathrm{EtNPr}_{3}+$ & -1.318 \\
\hline 13 & $\mathrm{BuNPr}_{3}{ }^{+}$ & -1.408 \\
\hline 14 & $\operatorname{MeN}(i-\mathrm{Bu})_{3}{ }^{+}$ & -1.375 \\
\hline 15 & $\operatorname{EtNMe}(i-\mathrm{Pr})_{2}{ }^{+}$ & -1.354 \\
\hline 16 & $\mathrm{Et}_{2} \mathrm{~N}(i-\mathrm{Pr})_{2}{ }^{+}$ & -1.332 \\
\hline
\end{tabular}

a molecular understanding of the effect of electrolyte structure on electrochemical stabilities. The reduction and oxidation potentials are determined by the LUMO and HOMO, respectively. ${ }^{45,53-55}$ For example, for a one-electron transfer ( $e$ is the electron charge, $\varepsilon$ represents the energies of the HOMO or LUMO, and A and B are constants that are determined by the choice of the reference electrode, solvent, model details, etc.): ${ }^{53-55}$

$$
\begin{aligned}
& V_{\text {Cathodic Limit }}=A \frac{\left|\varepsilon_{L U M O}\right|}{e}+B \\
& V_{\text {Anodic Limit }}=A^{\prime} \frac{\left|\varepsilon_{H O M O}\right|}{e}+B^{\prime}
\end{aligned}
$$

Based on Equations 1 and 2, a few models were suggested for the prediction of electrochemical windows of electrolytes (based on ab initio calculations, molecular dynamics, and density functional theory). ${ }^{53,54,56,57}$ Equations 1 and 2 imply that the LUMO and HOMO energy levels of molecules have a linear correlation with the corresponding standard reduction and oxidation potentials, respectively.

The LUMO energies of the cations shown in Scheme 1 were calculated using TD-DFT and are listed in Table II. A very poor linear correlation was found between the LUMO energy levels and the cathodic limits of quaternary ammonium ions (compounds 3 to 16) (coefficient of determination, $\mathrm{R}^{2}$, of 0.001 ; see Figure $\mathrm{S} 1$ ). This is not surprising because the cathodic limits of the quaternary ammonium ions are all scattered over a small $150 \mathrm{mV}$ window, with differences only in some cases beyond the experimental error. Another parameter to consider is that the measured cathodic limits are very close to but not identical to the thermodynamic standard reduction potentials shown in Equation $1 .{ }^{51}$ Hence a linear correlation between the LUMO energy levels and the cathodic limits in such a small potential range is not expected.

When linear regression is performed over a wider potential range, i.e., including $\mathrm{EMI}^{+}$and $\mathrm{NPyBu}^{+}$, which have much lower cathodic limits compared to the quaternary ammonium ions (entries 1 and 2 in Table I), a good linear correlation between the LUMO energy levels (obtained from TD-DFT) and the cathodic limits is obtained (see Figure 5). The range in the computationally predicted LUMO energy levels of the quaternary ammonium ions with different alkyl groups was approximately $0.2 \mathrm{eV}$. Using the linear approximation equation for the whole data set shown in Figure 5, the $0.2 \mathrm{eV}$ range in the LUMO energy levels corresponds to a $150 \mathrm{mV}$ range in the cathodic limits. This suggests that changing the chain length and type of branching of the saturated alkyl groups of quaternary ammonium ions results only in a minimal effect on the electronic environment of the positive nitrogen, as reflected in the LUMO energy levels.

The empirically observed linear relationship between the LUMO energy levels and the cathodic limits can be used to predict the effect

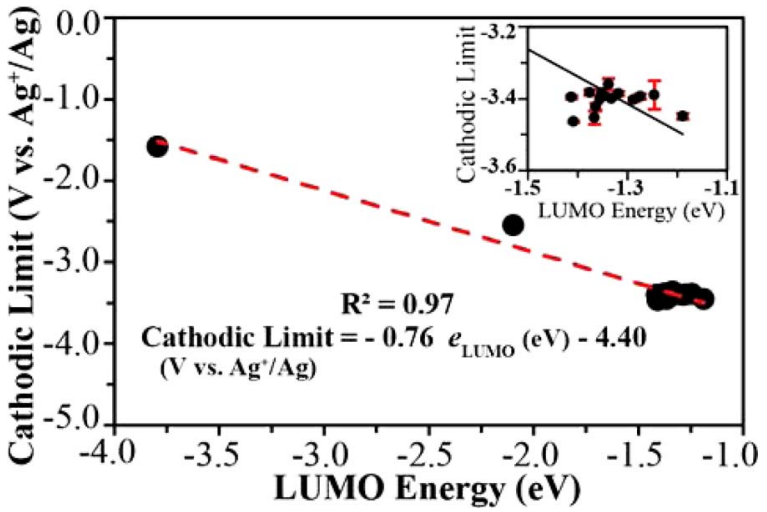

Figure 5. Correlation between the cathodic limits and LUMO energy levels. The cathodic limits obtained from the linear fit method are plotted vs. the LUMO energy levels obtained from the TD-DFT method. The dashed line shows the linear regression. The linear fit gives the cathodic limit (V vs. $\left.\mathrm{Ag}^{+} / \mathrm{Ag}\right)$ as $(0.76 \pm 0.037) \times e_{\text {LUMO }}(\mathrm{eV})-(4.40 \pm 0.06)$. The inset shows a zoomed-in view of the quaternary ammonium ions only. Cathodic limits obtained for $J_{\text {cut-off }}$ of 0.5 and $1.0 \mathrm{~mA} / \mathrm{cm}^{2}$ had a similar linear correlation with the LUMO energy levels.

of other structural variations on the electrochemical stability of quaternary ammoniums. For example, our model predicts that incorporation of oxygen and aromatic groups in the alkyl substituents of quaternary ammonium ions may substantially decrease the electrochemical stability of $\left(\mathrm{CH}_{3} \mathrm{CH}_{2} \mathrm{OCH}_{2}\right)_{2} \mathrm{NBu}_{2}{ }^{+}$and $\left(\mathrm{PhCH}_{2}\right)_{2} \mathrm{NBu}_{2}{ }^{+}$, with calculated LUMO energy levels of -2.79 and $-2.40 \mathrm{eV}$, as compared to $-1.36 \mathrm{~V}$ for $\mathrm{NBu}_{4}{ }^{+}$. This prediction agrees well with numerous experimental observations. ${ }^{10-15}$

Because of the minimal effect of the alkyl chain length on cathodic limits and the limited precision with which the cathodic limit can be quantified, the effect of the chain length on the tunneling probability of electrons (from the Fermi level of the electrode to the LUMO) could not be investigated experimentally. A computational study of the structure of these ions could provide us with an estimate of the chain length contribution to the tunneling rate. Although longer chains are expected to introduce more hindrance to the system, in order to evaluate the donor-acceptor distances, the dynamics of these chains in the vicinity of electrodes would have to be considered as well. This could be done using molecular dynamics simulations that are beyond the scope of this study.

\section{Conclusions}

The cathodic limits of quaternary ammonium cations with various alkyl substituents were measured using the conventional cutoff current density method at the cutoff current values of $0.1,0.5,1.0$, and $5.0 \mathrm{~mA} / \mathrm{cm}^{2}$. Cathodic limits were also obtained by a recently proposed method that is less biased by electrolyte mass transport and provides more reliable electrochemical stability limits. The new method is based on applying linear fits to the current-voltage polarization curve of the electrolyte at potentials below and above the onset of cathodic or anodic decomposition. It was shown that the chain length, type of branching, size, and steric hindrance of the saturated alkyl substituents have only a minimal effect on the electrochemical stability of quaternary ammonium cations. The LUMOs of cations were computed using time-dependent density functional theory with the IEF-PCM model. This showed that the cathodic limits have a linear correlation with the LUMO energy level of the cation. Moreover, we showed that the structure of saturated aliphatic alkyl substituents has minimal effects on the electronic environment around the positive nitrogen center and the LUMO energy level of the quaternary ammonium cations, which correlates linearly with the experimental electrochemical limit. We suggest that the effect of chain length on the tunneling rate in propylene carbonate solutions, if any, does not affect 
the cathodic limit significantly and falls in the range of experimental errors, and therefore cannot be inferred from the experimental results.

\section{Acknowledgments}

This project was partially supported by grant RL-0012-12 from the Initiative for Renewable Energy and the Environment of the University of Minnesota and a Graham N. Gleysteen Excellence Fellowship and a UMN Doctoral Dissertation Fellowship to M. P. S. M. We acknowledge Dr. Ana Vila Verde for informative discussions on molecular dynamics of our systems, and Dr. Aniko Nemes (Eötvös Loránd University) for her advice on the synthesis of the quaternary ammonium cations. S. K. acknowledges a scholarship from the International Max Planck Research School on Multiscale Bio-Systems.

\section{References}

1. E. J. Olson and P. Bühlmann, J. Electrochem. Soc., 160, A320 (2013).

2. K. Xu, M. S. Ding, and T. R. Jow, J. Electrochem. Soc., 148, A267 (2001).

3. M. Ue, K. Ida, and S. Mori, J. Electrochem. Soc., 141, 2989 (1994).

4. N. De Vos, C. Maton, and C. V. Stevens, ChemElectroChem, 1, 1258 (2014).

5. M. Ue, M. Takeda, M. Takehara, and S. Mori, J. Electrochem. Soc., 144, 2684 (1997)

6. M. L. P. Le, F. Alloin, P. Strobel, J. C. Lepretre, L. Cointeaux, and C. P. del Valle Ionics, 18, 817 (2012).

7. Y. Jin, S. Fang, J. Zhang, Z. Zhang, K. Yu, J. Song, L. Yang, and S.-I. Hirano, Ind. Eng. Chem. Res., 53, 2860 (2014).

8. S. Fu, S. Gong, C. Liu, L. Zheng, W. Feng, J. Nie, and Z. Zhou, Electrochim. Acta, 94, 229 (2013).

9. G. B. Appetecchi, M. Montanino, D. Zane, M. Carewska, F. Alessandrini, and S. Passerini Electrochim. Acta, 54, 1325 (2009).

10. Z. B. Zhou, H. Matsumoto, and K. Tatsumi, Chemistry, 11, 752 (2005)

11. C. M. Lang, K. Kim, L. Guerra, and P. A. Kohl, J. Phys. Chem. B, 109, 19454 (2005).

12. C. Liu, F. Xu, S. Feng, L. Zheng, H. Zhang, W. Feng, X. Huang, M. Armand, J. Nie, and Z. Zhou, Electrochim. Acta, 99, 262 (2013).

13. S. Fang, Y. Jin, L. Yang, S.-i. Hirano, K. Tachibana, and S. Katayama, Electrochim. Acta, 56, 4663 (2011).

14. Z. B. Zhou, H. Matsumoto, and K. Tatsumi, Chemistry, 12, 2196 (2006).

15. C. M. Lang and P. A. Kohl, J. Electrochem. Soc., 154, F106 (2007).

16. A. J. Bard, G. Inzelt, and F. Scholz, Electrochemical Dictionary, Springer: Berlin, 2008.

17. M. Ue, Electrochemistry, 75, 565 (2007).

18. M. Yoshimura, K. Honda, T. Kondo, R. Uchikado, Y. Einaga, T. N. Rao, D. A. Tryk, and A. Fujishima, Diamond Relat. Mater., 11, 67 (2002).

19. M. Finkelstein, R. C. Petersen, and S. D. Ross, J. Am. Chem. Soc., 81, 2361 (1959).

20. J. S. Mayell and A. J. Bard, J. Am. Chem. Soc., 85, 421 (1963).

21. M. C. Kroon, W. Buijs, C. J. Peters, and G. J. Witkamp, Green Chemistry, 8, 241 (2006).

22. K. Kim, C. Lang, R. Moulton, and P. A. Kohl, J. Electrochem. Soc., 151, A1168 (2004).

23. S. Fletcher, V. J. Black, I. Kirkpatrick, and T. S. Varley, J. Solid State Electrochem., 17, 327 (2013).

24. E. Runge and E. K. U. Gross, Phys. Rev. Lett., 52, 997 (1984).

25. R. Bauernschmitt and R. Ahlrichs, Chem. Phys. Lett., 256, 454 (1996).

26. M. E. Casida, Time-Dependent Density Functional Theory for Molecules, World Scientific: Singapore, 1995; Vol. 1.
27. M. P. S. Mousavi and P. Bühlmann, Anal. Chem, 85, 8895 (2013).

28. G. Inzelt, A. Lewenstam, and F. Scholz, (Eds.), Handbook of Reference Electrodes, Springer-Verlag Berlin Heidelberg, New York, 2013.

29. P. G. Sears, J. A. Caruso, and A. I. Popov, J. Phys. Chem., 71, 905 (1967)

30. H. M. Daggett, E. J. Bair, and C. A. Kraus, J. Am. Chem. Soc., 73, 799 (1951)

31. S. T. Goga, A. V. Lebed, and N. O. McHedlov-Petrossyan, J. Chem. Eng. Data, 55, 1887 (2010)

32. G. Zhang and C. B. Musgrave, J. Phys. Chem. A, 111, 1554 (2007),

33. F. J. Devlin, J. W. Finley, P. J. Stephens, and M. J. Frisch, J. Phys. Chem., 99, 16883 (1995).

34. A. D. Becke, J. Chem. Phys., 98, 5648 (1993).

35. A. D. Becke, Phys Rev A, 38, 3098 (1988).

36. C. T. Lee, W. T. Yang, and R. G. Parr, Phys Rev B, 37, 785 (1988).

37. E. Cances, B. Mennucci, and J. Tomasi, J. Chem. Phys., 107, 3032 (1997).

38. B. Mennucci, E. Cances, and J. Tomasi, J. Phys. Chem. B, 101, 10506 (1997).

39. J. Tomasi, B. Mennucci, and E. Cances, J. Mol. Struct.-Theochem., 464, 211 (1999).

40. S. Miertuš, E. Scrocco, and J. Tomasi, Chem. Phys., 55, 117 (1981).

41. S. Miertus and J. Tomasi, Chem. Phys., 65, 239 (1982).

42. P. Hohenberg and W. Kohn, Phys. Rev., 136, B864 (1964)

43. W. Kohn and L. J. Sham, Phys. Rev, 140, A1133 (1965).

44. M. J. T. Frisch, G. W., H. B. Schlegel, G. E. Scuseria, M. A. Robb, J. R. Cheeseman, J. A. Montgomery, T. Vreven, K. N. Kudin, J. C. Burant, J. M. Millam, S. S. Iyengar, J. Tomasi, V. Barone, B. Mennucci, M. Cossi, G. Scalmani, N. Rega, G. A. Petersson, H. Nakatsuji, M. Hada, M. Ehara, K. Toyota, R. Fukuda, J. Hasegawa, M. Ishida, T. Nakajima, Y. Honda, O. Kitao, H. Nakai, M. Klene, X. Li, J. E. Knox, H. P. Hratchian, J. B. Cross, V. Bakken, C. Adamo, J. Jaramillo, R. Gomperts, R. E. Stratmann, O. Yazyev, A. J. Austin, R. Cammi, C. Pomelli, J. W. Ochterski, P. Y. Ayala, K. Morokuma, G. A. Voth, P. Salvador, J. J. Dannenberg, V. G. Zakrzewski, S. Dapprich, A. D. Daniels, M. C. Strain, O. Farkas, D. K. Malick, A. D. Rabuck, K. Raghavachari, J. B. Foresman, J. V. Ortiz, Q. Cui, A. G. Baboul, S. Clifford, J. Cioslowski, B. B. Stefanov, G. Liu, A. Liashenko, P. Piskorz, I. Komaromi, R. L. Martin, D. J. Fox, T. Keith, M. A. Al-Laham, C. Y. Peng, A. Nanayakkara, M. Challacombe, P. M. W. Gill, B. Johnson, W. Chen, M. W. Wong, C. Gonzalez, and J. A. Pople, Gaussian 03, Revision C.02, Gaussian Inc.: Wallingford CT, 2004.

45. A. J. Bard and L. R. Faulkner, Electrochemical Methods Fundamentals and Applications, 2nd ed., John Wiley and Sons: New York, 2009.

46. J. Reiter, S. Jeremias, E. Paillard, M. Winter, and S. Passerini, Phys. Chem. Chem. Phys., 15, 2565 (2013)

47. Y. Jin, S. Fang, M. Chai, L. Yang, K. Tachibana, and S.-I. Hirano, J. Power Sources, 226, 210 (2013).

48. S. S. Moganty, R. E. Baltus, and D. Roy, Chem. Phys. Lett., 483, 90 (2009).

49. M. Morita, M. Goto, and Y. Matsuda, J. Appl. Electrochem., 22, 901 (1992).

50. A. M. O'Mahony, D. S. Silvester, L. Aldous, C. Hardacre, and R. G. Compton, $J$. Chem. Eng. Data, 53, 2884 (2008).

51. M. P. S. Mousavi, B. Wilson, J. Hu, A. Stein, and P. Bühlmann, J. Electrochem. Soc., 162, A2250 (2015).

52. Y. C. Lu, H. A. Gasteiger, E. Crumlin, R. McGuire, and Y. Shao-Horn, J. Electrochem. Soc., 157, A1016 (2010)

53. S. P. Ong, O. Andreussi, Y. B. Wu, N. Marzari, and G. Ceder, Chem. Mater., 23, 2979 (2011).

54. Y. H. Tian, G. S. Goff, W. H. Runde, and E. R. Batista, J. Phys. Chem. B, 116, 11943 (2012).

55. D. D. Mendez-Hernandez, P. Tarakeshwar, D. Gust, T. A. Moore, A. L. Moore, and V. Mujica, J. Mol. Model., 19, 2845 (2013).

56. H. Maeshima, H. Moriwake, A. Kuwabara, and C. A. J. Fisher, J. Electrochem. Soc., 157, A696 (2010).

57. H. Maeshima, H. Moriwake, A. Kuwabara, C. A. J. Fisher, and I. Tanaka, J. Electrochem. Soc., 161, G7 (2014). 